\title{
Plant Biology Experimental Courses in Universities: Status Quo, Limitations and Prospects
}

\author{
Zibin Huang \\ Correspondence: Zibin Huang, Guangzhou Dublin International College of Life Sciences and Technology, South China \\ Agricultural University, Guangzhou, 510642, China.
}

Received: December 15, 2021

Accepted: January 15, $2022 \quad$ Online Published: January 17, 2022

doi:10.11114/ijce.v5i1.5449

URL: https://doi.org/10.11114/ijce.v5i1.5449

\begin{abstract}
Plant biology, as a significant compulsory course for biological science students, is intuitive and practical, which plays a unique role in improving students' comprehensive quality and cultivating their innovation ability. Because of its strong practical characteristics, the experimental course is of great necessity in the study of this course. This paper analyzes the traditional teaching mode of plant biology experiment, as well as its shortcomings in modern teaching, and puts forward diversified reform methods based on the development of contemporary plant biology to promote the teaching mode of plant biology experiment to meet the needs of contemporary students on this subject. Based on the rapid development of modern science and technology, this paper includes the teaching contents, teaching methods, and assessment system of plant biology experiments, and discusses them respectively. This paper aims to improve the teaching efficiency of modern plant biology experiments and help to achieve the goal of efficiently improving students' innovation and scientific research ability.
\end{abstract}

Keywords: plant biology, experimental course teaching, diversification reform, literature review

\section{Introduction}

Plant biology is a basic course for university students majoring in biotechnology. As professional basic courses play a significant role in university courses, they not only have the particularity of the discipline but also lay a solid foundation for specialized courses. The degree of the mastery and application of professional basic course knowledge directly affects students' learning efficiency, interest, and ability to engage in professional work. Therefore, the learning stage of professional basic courses is a critical period for the cultivation of students' ability, which can fully exploit students' potential, help to cultivate their capacity to analyze and solve problems, foster the spirit of innovation and assiduous study, form systematic scientific thinking concepts, and improve students' comprehensive quality (Yixidawa, 2013). That is to say, the educational pattern and the quality of professional courses are particularly cardinal. So its current situation and limitations need to be analyzed with the rapid development of education in the new age and based on this, the reformation and prospects of the curriculum teaching plan are discussed to ensure that the professional course education in universities will not be behind the times. Plant biology is the basic course of plant life science research, which is devoted to plant morphology, structure, physiology, classification, genetic variation, and evolution as well as their relationship to the environment (Teng, 2013). Meanwhile, it is also the basis of professional course learning, such as ecology, genetics, developmental biology, and so on (Zou, 2014). The content of this course is quite abundant, involving a wide range of knowledge, and relevant concepts featured with abstract, practical, and knowledge that is difficult to memorize (Teng, 2013). The strong intuitiveness, practical discipline nature of plant biology leads experimental teaching to be an essential part of the whole teaching process. Botany has a unique role in classroom teaching which is generally unable to be replaced ( $\mathrm{Lu} \&$ Zhou, 2013; Yuan et al., 2020) to develop students' ability to analyze and solve problems and improve their comprehensive quality and innovation ability. It is not only a significant basis for all the professional experimental courses of biology discipline, but also a critical practical subject to train students' scientific research, practical ability, and comprehensive quality. (Han, 2005). Therefore, plant biology experiment courses occupy a vital part in the cultivation of students' scientific research ability (Gong, 2006; Liang et al., 2012).

For university students majoring in biology, plant biology experiment education should be reformed by keeping pace with the times to reach their basic teaching and practical needs. Plant biology experiment should undoubtedly be based on experiment, which means it studies the phenomena, rules, and essence of plant life activities (Gong, 2010; Liang et 
al., 2012). Therefore, plant biology courses need to be consolidated through experiments and field practice to a certain extent. But in recent years, it is not uncommon to see the development of the discipline, the improvement of the professional training scheme, the change of students' quality, and the innovation of technology. Plant biology experiment teaching content and methods are still continuously improved to meet the needs of real-time development, and what is more important is to promote students' participation and improve the learning enthusiasm (Gu, et al., 2019). This paper will focus on the current teaching reformation of the plant biology experiment, systematically elaborate on the present situation of the subject and analyze the deficiencies of the subject education. At the same time, this paper will regard the improvement of the efficiency of college students to acquire knowledge in this course as the core purpose, combined with the current college education to put forward the prospects of the reformation of this discipline, and look forward to the future of the reform of plant biology.

\section{Statu Quo and Limitations of Plant Biological Experiment}

There are some limitations in the experimental teaching of plant biology in colleges and universities. With the rapid development of science and technology, the traditional experimental teaching of plant biology in universities cannot well meet the demand for high-quality talents in the new century in terms of teaching content, teaching methods, and experimental means (Liu, 2011). For a long time, the goal of teaching plant biology experiments was mainly to verify the theory, especially to deepen the understanding of theoretical knowledge. Experimental teaching is likely to, ignore the cultivation of students' comprehensive ability and innovative consciousness, which greatly shackles students' thinking, restricts their vision, and is not conducive to students' initiative and creativity. Outdated experimental teaching methods and backward teaching means also seriously affect the teaching quality (Wang, 2009; Yu, 2010). To some extent, the premise of the experimental curriculum reform of plant biology is to fully understand the modern experimental teaching model of plant biology.

It is a necessary condition for the reform based on a full understanding of the present situation of plant biology experimental education. At present, the experimental teaching of plant biology in agricultural universities is mainly based on confirmative experimental teaching. The main goal is to train students to master basic experimental skills and methods and improve their scientific research level. Teachers fully explain the teaching design and arrangement of plant biology experiments before the experiment and guide students to complete the experimental teaching content step by step during the whole experiment process. The experimental teaching of plant biology based on confirmatory experiments certainly teaches most students certain experimental methods and experimental operation skills, but it is lacking in developing students' innovative ability and creative thinking in experimental teaching. Meanwhile, how to guide students to conduct exploratory learning and improve their scientific research ability should be a significant task for contemporary plant biology experimental teaching (Yang et al., 2018).

\subsection{Experimental Teaching Materials}

Most of the experimental courses of plant biology in universities lack specialized and systematic experimental course materials. Most agricultural universities generally adopt botany experimental textbooks as reference textbooks (Yang et al., 2018), but some plant biology textbooks were written earlier and fail to adapt to the rapid development of modern plant biology. Also, some experiment textbooks are too detailed. In the process of specific experiments, students only need to follow the instructions according to the required process, without searching for information, thinking, and innovation, which seriously affects students' interest in experimental classes and inhibits their initiative to participate in experiments (Li, 1998; Zhou, 2000). In other words, in the actual teaching process, the theory in the textbook should keep up with the changes of the time, and materials about plant biology experimental teaching are far behind, which means experiments may be conducted without a corresponding matching laboratory. In addition, due to the limited experimental hours in each part, experiments with relatively simple experimental design and the short cycle can only be selected, which may dilute students' enthusiasm in doing experiments (Su et al., 2016). Therefore, it is difficult to cultivate students' interest in learning and macro thinking, thus making a negative difference to the teaching effect.

\subsection{Experimental Teaching Methods}

Contemporary botany experimental teaching methods in universities are mainly carried out in the "teacher-oriented and student-assisted" way (Yang et al., 2018). First of all, the experiment teacher explains the experiment method, steps, and tips that require attention, and students complete the experiment content according to the teacher's explanation of the experiment. Second, in the contact with students and class feedback, it shows that most students do not know the specific content of the experiment before the experiment class began and only complete the experiment according to the teacher's instructions. If they do not understand anything, they will directly ask the teacher for help, which leads to the lack of independent thinking space and innovation ability of the experiment discipline. At the same time, only a few students have written the experiment report in advance, but they just finish the experiment mechanically according to the arrangement of the experiment course, following the instructions instead of gaining the knowledge and skills (Yang 
et al., 2018). Grounding teacher's demonstration, students lack enthusiasm for learning plant biology, and they just need to go to class and follow the instructions. At the same time, the experimental teaching of plant biology is attached to the theoretical class, which has certain deficiencies (Jia, 2016), which are mainly reflected in the fact that students focus on theoretical knowledge and ignore experimental courses. Therefore, students are likely to lose the initiative of doing experiments. Such a method is naturally difficult to achieve the purpose of improving students' abilities. The teacher-oriented and student-assisted teaching method can no longer adapt to the rapid development of contemporary biology. That is, teaching methods should be changed to improve students' creative thinking and practical ability (Yang et al., 2018).

\subsection{Experiment Teaching Evaluation}

The evaluation and scoring system of plant biology experiments in modern universities is still in the developing stage. As the plant biology experiment course depends on the theory of plant biology courses, it has not formed a systematic discipline with a certain scale under the current system. Without the formation of examination with diverse ways, students finally obtained grades of the experiment only account for a small part of the course of the botany (Yang et al., 2018). As a result, students only pay attention to the theoretical courses of plant biology without enough attention to the experimental courses, which reduces the enthusiasm and initiative of students in learning experimental courses of plant biology. The fact is that they just finish the whole experiment mechanically, and do not carefully prepare and review the experiment of plant biology. In addition, due to the problems in the experimental teaching materials, many students copy the experimental purpose, experimental content, experimental equipment, and experimental steps in their reports, which results in a great similarity of their without sufficient differentiation. The above problems, to a large extent, hinder the subjective initiative of students in the experiment process, and cannot well implement the original intention of opening experimental courses. Using a variety of assessment methods can improve students' learning enthusiasm, conscientiously complete the content of the experiment arrangement. Nowadays, the examination methods of plant biology experiments in universities have not achieved the purpose of improving students' ability, so it is necessary to perfect the examination system of this subject by using diversified evaluation methods.

\section{Prospect of the Reform of Experimental Teaching Content in Plant Biology}

\subsection{The Optimization of Preparations of Experimental Teaching}

\subsubsection{Compile and Select Targeted Teaching Materials}

Teaching material is a significant factor affecting the teaching quality of plant biology experiments. There is a lack of experimental teaching materials with strong pertinence in experimental teaching of a plant biology course, and the compilation of teaching materials in line with experimental teaching of the course is the key step to effectively improve the quality of the teaching of botany experiment (Yi, 2011). Therefore, if the existing conditions permit, all the teachers of plant biology teaching and research group can supplement the experimental teaching materials, such as giving the experimental results directly so that students can make flexible changes and find out a variety of experimental methods. Secondly, another approach is to leave a blank in some key steps so that students can think and discuss in advance, consult materials and ask teachers if they don't have great comprehension, and conduct experiments after solving key problems. Finally, different levels of thinking questions are set up in the experimental teaching materials according to the experimental content to gradually deepen the difficulty of thinking and guide students to learn to solve difficult experimental problems by degrees (Wang, 2009; Yang et al., 2018). At the same time, in the compilation of plant biology experiment textbooks, experiments can be arranged according to the ratio of 5:3:2, with 5 as a basic experiment, 3 as a comprehensive experiment, and 2 as an independent creative experiment. Such coexistence of various forms of experiments can improve students' practical ability, strengthen the practical ability and improve the innovation ability. Students' scientific methods, scientific thinking, and innovation ability can be enhanced to a certain level.

\subsubsection{Set up Scientific Plant Biology Teaching Plans}

Setting up a teaching plan scientifically can improve the teaching quality effectively. Teaching content is the core of cultivating innovative talents, enabling the basis to promote the profession, to cultivate students' capability of developing and designing applications in learning professional basic course, to target in the study and application of the professional course (San, 2008). The scientific experimental teaching system and content not only helps students to master knowledge, skills, and methods but also helps students to cultivate their scientific thinking and innovation ability and improves their comprehensive quality, which is a significant basis for improving the teaching quality of plant biology (Teng, 2007; Deng et al., 2014). Therefore, setting up a plant biology plan rationally is the key step to cultivating applied talents in colleges and universities. Thus, according to the actual situation of plant biology teaching in universities, the experimental teaching plan and teaching syllabus can be revised for the practical teaching arrangements of plant biology to be adjusted appropriately, so that the learning time of theoretical courses and practical courses of plant biology can be appropriately increased (Yixidawa, 2013). At the same time, on the foundation of 
clarifying the basic and core requirements of teaching content, properly grasping the depth and breadth of each knowledge point is required. Teachers should pay close attention to and track the new development direction of the major that continuously turns up, constantly add new problems, new phenomena, and new theories related to the course, combine knowledge content and include cutting-edge knowledge and interdisciplinary knowledge into the teaching content (Liu, 2010; Yixidawa, 2013). Reintegrating the traditional botany experiment according to the specific gradient, to avoid the repetition with other courses as much as possible, to establish a new system of hierarchical and modularized experimental teaching content by effectively connecting and complementing experimental skills within the discipline. In the limited time, part of the same type of experiments is integrated to help students to grasp the key points and difficulties of experimental teaching content, so that students can obtain the maximum effect in the limited time and save the time spent on experiments (Liang et al., 2012; Yixidawa, 2013; Lu \& Zhou, 2013).

The content of traditional plant biology experiments is mostly confirmatory experiments. According to the requirements of the experimental teaching syllabus, the opening time of the laboratory course and the regional characteristics of plants are further integrating and optimizing the experimental teaching content so that the experimental teaching content is divided into three modules: basic experimental module, comprehensive experimental module, and design experimental module. First of all, the basic experiment module is in the leading position among the three modules of the plant biology experiment, which is composed of verification, observation experiment, and basic skills. Its content covers the morph and structure of plant cells, the morph and structure of plant organs and their development, and the verification of main characteristics of various plant groups and all that. The training of basic experimental skills and the consolidation of basic theoretical knowledge of plant biology is mainly carried out to help students master the basic skills of plant biology experiments, the morphological and structural characteristics of plants and the main characteristics of various groups of plants, and closely combine theory with practice (Deng et al., 2014). Secondly, the comprehensive experiment in the module set is mainly based on the complexity of scientific phenomena, the use of a single knowledge or a single discipline knowledge often cannot make a satisfactory explanation to complex problems, and the module of the experimental project is set based on the students with basic experiment skills and related theory knowledge, to further strengthen the ability of experimental operation and comprehensive use of knowledge as the core, the setting means to train students to have to ability to comprehensively use knowledge to analyze problems and solve problems. In addition, in the design experiment module, students select the topic, on the grounds of the knowledge they have learned, design the experiment purpose, plan, steps, and so on through searching relevant information to finish the experiment independently, analyze the experimental results and process the experimental data and write the experimental report. The purpose of designing experiments is to cultivate students' independent thinking ability, rigorous scientific attitude, teamwork spirit, and innovative consciousness, and also stimulate students' initiative and creativity (Jia, 2016). Finally, in the light of the theory of plant biology teaching progress and seasonal changes of plants, taking such measures as changing the original time to carry out an outdoor study to that of the second study can achieve the close combination of theory and practice knowledge, and can also efficiently alleviate the pressure of the students' learning, which can offer students enough time to learn and absorb knowledge and effective coordination with other basic courses (Yixidawa, 2013). By setting up this systematic teaching plan scientifically, the knowledge of each module of plant biology experiment can be more relevant to the training of students' scientific research ability. From the basic experiment to the design experiment, the requirements for students also correspond from the application of basic knowledge to the application of extended knowledge, which can also consolidate and improve the ability of students in the experiment step by step

\subsection{Reserve the Advanced Knowledge of Experimental Teaching}

In the teaching reform of plant biology, the advanced knowledge reserve of experimental teaching plays a significant role. The knowledge reserve of experimental teaching can be grouped into three parts: the transition from theoretical courses to practice, the training of basic experimental techniques, and the requirements for students' preview before class. First of all, the teaching content of plant biology experiments can be divided into two courses, botany experimental principle, and plant biology experiment, which are organically combined and complement each other. Therefore, the plant biology part can be explained and sorted out in detail by all botany course teachers before the experimental course, to promote the learning of combining theory with practice (Zhang et al., 2016) and help students to achieve a good transition from plant biology course to plant biology experiment. Secondly, the course can be arranged for the basic instrument training in the first 3 weeks of the semester. Students can preview through the teaching materials before class, and the experimental teacher will explain the basic principles of the basic technology of the microscope and the operation method of the microscope for students in class. After the explanation, students took in-class operational tests after having some exercises. Experimental teachers should sign on the instrument use certificate for qualified students, and students can conduct experiments with microscopes (Deng et al., 2014). Finally, to deepen students' understanding of experiments, modern teaching methods can be used to help students broaden their 
horizons. For example, experimental items, principles, procedures, and other relevant information on plant biology can be posted on the experimental center website before the semester starts. At the same time, to ensure the preview effect, students can take a pre-class quiz and score it 10 minutes before the class begins, which will be included in the total score of the experimental class. At the beginning of the experiment class, the teacher only gives a brief reminder of the main points and precautions of the experiment, leaving more time for students to observe by themselves, and then solve the problems in the experiment through mutual discussion. Finally, the teacher makes a summary. The optimization of experimental content plays an important role in the whole experimental teaching of plant biology, which determines the quality of contemporary students' learning content and the reform way of experimental teaching (Deng et al., 2014).

\section{Implications of Botany Experimental Teaching Reform}

\subsection{Realize the Diversification of Teaching Methods}

The diversity of teaching means contributes to the efficient input of teaching content. For professional basic courses, the teaching content is mainly the principle content or equation is derived from the classic theory. At present, this course is given priority to with teachers' teaching style, teaching team-based different teaching contents with case teaching, project teaching, scene teaching method, and PAD class (bipartition class) teaching mode and so on. It is also practical to apply the modern teaching means, multimedia, video, and other teaching materials and examples with pictures, texts, sounds, and images to visualize and materialize the abstract teaching content, to provide students with more intuitive and more wonderful information within limited class hours and stimulate students' interest in learning (Yixidawa, 2013). The combination with information platform guides students to look for information to solve some problems in life or explain a phenomenon in production. Diversified, informationalized teaching methods strengthen the students' consolidation and understanding of the theoretical knowledge, and therefore guide their thinking in doing experiments. It can also have a certain effect to urge students to study in the active teaching activities to promote the cultivation of students' innovation consciousness and inspire the students' understanding and thinking of course or professional, (Zhu, 2015). These methods are the benefits of a variety of teaching methods. The following are possible teaching methods for experimental plant biology reform.

\subsubsection{Observation and Comparison Teaching Methods}

Observing and comparing teaching methods can help students master professional knowledge more efficiently. In the process of experimental teaching of plant biology, based on the requirements of experimental content, students should be guided to observe and compare. For example, the observation of the morphological structure of plant tissue, collenchyma, and the morphological structure of conduit and sieve tube in conducting tissue. Inviting just one or two students, for example, oral compare two kinds of mechanical tissue morphological structure difference. The instructor will do review and correction through such learning methods in the process of the experiment so that students can not only better master harder morphological structure and knowledge point but also can complete the experiment content. At the same time, it is easier to remember for structural characteristics of the plants (Yang et al., 2018).

\subsubsection{Heuristic Teaching Methods}

Heuristic teaching can guide students to think actively and solve difficult problems. According to the experiment content, for the questions students ask, teachers invite them to look at the specific research object instead of answering immediately, and then utilizing rhetorically questioning the students, which means this teaching method can achieve the goal that students answer questions of themselves. Addressing the questions through their observation can greatly deepen the understanding and master the structural characteristics. Such teaching method reform gradually allows students to participate in the experimental teaching of plant biology, improve the subjective initiative of learning, learn to think and solve problems and achieve better teaching results.

\subsubsection{The "Students First, Teachers Second" Teaching Method}

Using a "student-dominant" teaching method can improve students' sense of participation in the experiment process. In the experimental teaching process, 3 to 4 students are regarded as a learning group to discuss all the content of the experiment together, think positively, put forward problems to discuss solutions together, and enable the students to experience the fun of the experimental process. As the teacher acts as the role of answering the most difficult question as well as students in the dominant position of the whole experiment, adding a variety of teaching methods also with the means which can attract students can greatly improve the enthusiasm of students in learning. Asking and searching when students do not understand can put the theoretical knowledge and experiment of practical link (Yang et al., 2018).

\subsection{Reform Botany Experiment Teaching in Information Age}

\subsubsection{Establishment of "Internet + Task-driven" Approach}

The establishment of "Internet + Task-driven" can provide a new approach for the reformation of plant biology in line 
with the age. In the traditional teaching mode of botany, teachers have always been the center of the classroom and have always emphasized the teaching of systematic knowledge of botany (Tan, 2012; Ahan \& Yang, 2014). The task-driven teaching method is a kind of teaching mode in constructivism theory. It is a new student-oriented teaching idea, which emphasizes students' initiative in the teaching process. It is implemented by teachers to design the teaching content into specific tasks so that students can learn with real tasks, which not only achieves the teaching goal but also cultivates students' ability to analyze and solve problems. The task-driven teaching method emphasizes that students' learning must be combined with tasks or problems, and students take real tasks to learn so that they have the initiative. Therefore, the whole learning process is not only the transmission of knowledge but also the process of students' active construction of knowledge experience $(\mathrm{Li}, 2015)$. With the development of network technology, the arrival of databases, and artificial intelligence time, plant biology subject content is also rapidly expanding and constantly updated. As the "Internet Plus" is strongly advocated by the country, the task-driven teaching combined with the Internet introduced to the plant biology experiment teaching will be a positive attempt.

The application of the "Internet + task-driven" method in plant biology can be carried out in the following ways. First, team members carry out investigations in the form of team exploration with real tasks. Secondly, members can carry out surveys with the help of various applications and databases on mobile Internet terminals. Finally, the group introduces the report which includes species and morphological characteristics of plant resources in the campus in the form of PPT. The whole class carries out class discussion, to realize the teaching goal of asking students to actively discover, think and solve problems. The implementation of the "Internet + task-driven" teaching method makes the abstract knowledge of textbooks come into students' lives vividly, promotes the internalization of theoretical knowledge in class, cultivates students' innovative thinking and teamwork spirit, and arouses students' interest in independent learning. This student-centered teaching method not only stimulates students' interest in learning but also cultivates their ability to acquire and explore knowledge by using modern tools (Yuan et al., 2020).

\subsubsection{Multimedia}

Multimedia means can bring convenience to experimental teaching. In previous experimental teaching, there were common problems such as unclear observation objects and chaotic teaching order. However, the multimedia experimental teaching method can effectively overcome the limitations brought by traditional teaching methods and make learning content lively and interesting (Lu \& Zhou., 2013). By multimedia teaching, food, drug, or plants with ornamental purposes in our lives, even the plants that students are familiar with and teaching content can be in the form of pictures or video merged into the field of multimedia courseware. The detailed theoretical knowledge content reflects the observation, made clear the specific structure, lets the student observe purposefully. It enables students to understand unfamiliar botanical terms and concepts more intuitively and vividly, inspires them to connect what they have learned in class with real life, and improves students' ability to integrate and solve practical problems (He \& Abasi, 2012; Lu \& Zhou, 2013). At the same time, for some operational experiments, the teacher demonstrates alone with a group of students around, resulting in teaching disorder. However, videos can be directly demonstrated to avoid the disorder through multimedia teaching (Lu \& Zhou, 2013). Survey results show that $98 \%$ of students believe that multimedia teaching is of great help to understand concepts, deepen memory and improve learning interest (He \& Abasi, 2012).

\subsubsection{Modern Electronic Equipment and the Internet}

The high-pixel camera function of smartphones can play a great role in plant biology experiments. In the experiment that requires microscope observation, most students have learned to take micrographs with the lens of a mobile phone aimed at the eyepiece. After taking micrographs in multiple horizons, they can draw pictures concerning the pictures. The following is the convenience brought by the camera function of mobile phones in the operation process of plant biology experiments. First, the LED flash of mobile phones can significantly enhance the fluorescence of chloroplast pigment, so that the fluorescence observation is clearer and the operation is more convenient. At the same time, mobile phones can not only take photos of chloroplast pigment stratification in saponification reaction and dynamic color change process of chloroplast pigment extract in magnesium ion substitution reaction but also take the absorption spectrum of chloroplast pigment by spectroscope (Gu et al., 2019). Smartphones have powerful functions. In addition to call and SMS functions, they also have all the functions of handheld computers. Besides, they support third-party software with powerful expansion functions and can provide personalized function design (Zhang, 2015). For example, in a classroom with large numbers of students, not every student can see and hear what the teacher is teaching, and the communication function provided by smartphones can effectively solve this teaching limitation. Moreover, students can also make full use of the powerful multimedia function of mobile phones to learn plant biology, such as using PPT to check courseware, timely marking in PPT. Students can also use the editing function of the photograph, mark plant name, place of origin, with similar plants edited on the same picture to facilitate comparison and understanding. In the process of experimental teaching, students are also asked to give full play to the camera function of mobile phones, take 
pictures of uncertain structures immediately and point them out to the teacher with pertinence (Lu \& Zhou, 2013).

At the same time, the correct use of network convenience can improve teaching efficiency. The network is a double-edged sword: correct guidance can promote learning progress; being addicted to the network may be unable to extricate themselves. In the teaching process, teachers should take advantage of the situation, foster strengths and circumvent weaknesses, and give full play to the auxiliary role of the network. QQ is the main media for students to communicate with each other on the Internet. After class review, when students encounter problems, they should ask questions at any time so that they can be targeted and have timely guidance. By communicating with students, teachers can know where the teaching weaknesses are in the lectures. For common questions, it is necessary to answer them in time in the next class. Students can also ask about plants they don't know through QQ (Lu \& Zhou, 2013).

\subsection{Reform Botany Experiment Extra-Curricular Teaching}

Opening a second class for students is beneficial to students' self-study and consolidation of knowledge. First of all, the herbarium and plant laboratory related to plant biology will be opened, and independent practice activities will be carried out around the subject to be explored. Experimental and theoretical classes of plant biology will be comprehensively combined with extra-curricular scientific and technological activities to conduct colorful second-classroom teaching activities. It is of great significance to make full use of plant biology knowledge to carry out the list of plant research, Chinese herbal medicine research, botanical garden plant, and other activities. For example, students should be trained to learn how to comprehensively use their knowledge to discover problems and improve the ability to analyze and solve problems, especially for the research of plant biology in the future to lay a solid foundation. At the same time, students should be guided to conduct independent practice activities centering on research topics, to realize the organic unity of theory courses, experimental courses, classroom teaching, and extracurricular scientific and technological activities ( Dai, 2020).

Setting plant field practice is helpful to improve students' learning enthusiasm. Going out of the campus and having close contact with plants in the natural environment outside the campus is conducive to deepening the impression of ecological knowledge (Lu \& Zhou, 2013). Through the practical teaching link of field practice, the knowledge of botany classification is consolidated, and the spirit of solidarity, friendship, and mutual help among students and teachers is enhanced (Liang et al., 2012).

Conclusion and discussion after class play a significant role in learning plant biology experiments. With unified experimental discussion at the end of the experiment, the student will discuss the problems discovered in the experiment, the experimental phenomenon, experiment design's train of thought and related problems, and the development of experimental project problems with the teachers. Making the student to the whole process of the experiment has a deeper level of understanding and grasp, to solve the problems in the experiment, therefore expanding students' knowledge (Deng et al., 2014).

It is a way to maximize the practical function of the laboratory by bringing the graduation thesis design into the laboratory under the guidance of teachers. At the same time, the design and completion of a graduation thesis is the most effective way for undergraduates to comprehensively improve their professional skills in the four years and plays a significant role in the whole teaching plan (Bai, 2008). In the process of thesis guidance, systematically training students' scientific research ability enables them to apply the knowledge that they have learned to practice, improves the student's ability of professional accomplishment and scientific research, and cultivates innovative talents to adapt to the market demand, but also greatly promotes the improvement of the teachers' scientific research level, highlights the complementary effect of teaching and scientific research (Dai, 2020). First of all, students can be encouraged to actively participate in the teacher's scientific research projects. Meanwhile, teachers can absorb students to participate in academic research. Teachers should guide students to use spare time to consult the literature, sort out data, formulate research plans, carry out scientific research, make statistics and analysis of scientific research data, write papers or reviews, and organize exchanges and discussions (Lu \& Zhou, 2013). Secondly, by closely centering on the knowledge system of plant biology and fully combining teachers' scientific research projects, students are encouraged to participate in plant biology research activities and join in botany research work with teachers (Lu \& Zhou, 2013; Dai, 2020). For example, participating in the overall development of the research can apply for the student's professional knowledge, improve students' scientific literacy, cultivate students' innovative ability and comprehensive quality and encourage students to apply for colleges and universities in the college scientific research project on basis of their interest. It can not only cultivate students' ability of project operation, but it can also foster the innovation ability of students (Yu et al., 2017). 


\subsection{Reform Assessment of Botany Experimental Skills}

\subsubsection{Improve the Assessment and Evaluation System, and Pay Attention to Experimental Effects and Tests}

Separate classes and examinations in plant biology can increase the importance of this course in all courses. The basis and premise of the reformation of plant biology experiment course are to improve students' attention to experiment course, but the traditional experiment course is attached to the theory course so that students' attention to experiment course is not high. In order to solve this problem, plant biology experiments can be set up as a separate course from plant biology and given independent credits. Nevertheless, a separate examination is set up at the end of the semester, with a total score of 100. Students whose scores are below 60 points are required to take a make-up examination (Su et al., 2016). Separate courses and examinations are effective teaching reforms, which can be used to test the degree and level of students' mastery of knowledge and the ability of students to master basic experimental skills in experimental teaching (Wang, 2000). It is a complex expressive activity for students to complete the experiment, which should be adapted to clear evaluation standards, flexible evaluation methods, and effective evaluation results (Xiao, 2001). Therefore, a variety of assessment methods should be used to achieve a truly fair and just comprehensive assessment.

Perfecting the examination system is a significant part of reforming the examination system of plant biology. Under the existing plant biology experiment examination system, the examination system should be improved by reforming the coexistence of various examination methods, such as microscope operation skills, freehand section making, innovative ability, and comprehensive ability in the experiment process and all that. The total score of a plant biology experiment is 100 points, which should include $50 \%$ of the usual score of experimental attitude, experimental theory, operation skills, experimental report, and other aspects, and 50\% of the final assessment ( $\mathrm{Li}, 1999$; Wang, 2009). Bonus points will be given to the students who speak boldly and ask questions in the experiment, prepare carefully and complete the experiment report conscientiously in the experiment teaching section. This teaching method and assessment method can avoid only seeing experimental reports to give experimental results, and multiple assessment methods coexist, which is more fair, reasonable, and easier for students to accept. Additionally, students can be more active in learning and like experimental courses of plant biology (Yang et al., 2018). Moreover, a strict attendance system should be established. If one class is absent for any reason, the attendance and operation points of the experiment should be deducted (Li, 1999). However, absent students can make up for the experiment in the laboratory according to their own time to avoid the deduction (Yang et al., 2018). Finally, the writing of the student experiment report should be standardized. In the experimental procedure part, students are required to record the real experimental process and data, and the experimental report should be expressed in their language instead of copying the experimental instructions. Students are encouraged to put forward creative ideas and understanding, which will lay a foundation for future students' research papers. (Su et al., 2016)

\subsubsection{Optimize the Experimental Performance Assessment System}

The experimental examination is an important method to check the teaching quality of teachers and students to master the basic experimental skills and theories. Evaluation of teachers is mainly used the secret way. For instance, comments are given by the students about the teachers' teaching level, the process of tutoring, guiding inspiration, correcting the experiment report, and the sense of responsibility. The teachers can see results and find the insufficiency in their work. Teachers attaching great importance to the students' information feedback and suggestions for teaching can improve the experimental teaching. For the assessment of students, the way of reading the experimental report has a great influence on their learning enthusiasm. Scientific and objective evaluation of students' experimental scores plays a guiding role in the coordinated development of student's knowledge, ability and quality, otherwise, it will frustrate students' enthusiasm (Cheng, 2006; Deng et al., 2014). Specific practices are as follows. After each experiment, the teacher will correct the experimental report of one group. The group will discuss the correction principle and grading standard with the teacher, and then correct the experimental report of other groups. Before the next experiment, the group correcting the experiment report is responsible for commenting on the error-prone questions and their correct answers. All groups take turns to participate in the correcting and commenting of the experiment report. All students can re-draw and re-write the experiment report, and the teacher will mark it and record the highest score (He \& Abasi, 2012).

\section{Concluding Remarks}

This paper reviews the present situation, limitations, and reform prospects of the experimental teaching of contemporary plant biology. The reform of the course needs to keep pace with the time. The experiment teaching materials of contemporary plant biology education cannot update timely, and relatively single experiment teaching methods and experiment examination systems are still underdeveloped. Therefore, teachers can output the contents of the teaching plan, and students can also learn a lot from the course through reforming a teaching plan scientifically, using diversified teaching methods, especially within "Internet Plus", and developing the evaluation system. Teaching practice shows that through the "task-driven" implementation within "Internet Plus", students' independent and exploratory learning ability 
can be significantly improved, and at the same time, new teaching methods can also change the traditional "teacher-centered" one-way indoctrination mode of experimental teaching, and truly gives the initiative in class to students. In the context of the rapid development of modern science and technology, the combination of education methods and modern science and technology can not only highlight the advantages of science and technology, improve the efficiency of education, but also ensure the real-time update of teaching content, and avoid the mismatch between teaching content and the progress of contemporary plant biology research. To keep pace with the time of teaching methods can improve the students' interest in learning, motivate them to explore the mystery of the plant world, and help them to apply knowledge to practice by solving practical problems. Further students can make full of its value, make professional accomplishments and improve their ability to do experiments, which means they can be cultivated to meet the demand of social development and market as applied innovative talents. Future research can be conducted to explore how to undertake experimental teaching of plant biology through network teaching platforms, such as online simulation experiments and other convenient teaching methods. Research on the teaching mode and system can be further studied to provide more insights for both theoretical studies and practical teaching.

\section{Acknowledgements}

As research assistant of Jialiang Chen, the author would like to express sincere thanks for his insightful suggestions and constructive feedback on content relevance, content sufficiency, organization, and language quality in an earlier version of this paper.

\section{References}

Ahan, J., \& Yang, X. (2014). Exploration and practice of improving botany classroom teaching effect. Journal of Yili Normal University: Natural Science Edition, (3), 73-75.

Bai, L. (2008). Discussion on the talent training mode of biology specialty in newly-established undergraduate colleges. Journal of Hengshui University, 10(4), 111-113.

Cao, S., Han, J., \& Liu Y. (2008). Research on the implementation of application-oriented undergraduate talent training mode in specialized basic courses. Science and Technology Innovation Review, (30), 214.

Cheng, Y., Meng, Q., \& Liu, C. (2006). Research on the quality evaluation system of basic experimental teaching in colleges and universities. Forum on Higher Education, (2), 116-118.

Dai, Y. (2020). Reform and exploration of plant biology experiment. Education and teaching forum, 9(37), 391-392.

Deng, X., Long, W., Xiao, C., \& Hu, W. (2014). Exploration and practice of experimental teaching model of plant biology. Journal of Anhui Agricultural Sciences, 42(32), 11609-11610.

Gong, S., Jiang, Y., \& Liu, S. (2006). The reform of botany practice teaching and the cultivation of students' innovation ability. Higher Science Education, (3), 104-107.

Gu, H., Jin , J., \& Qian, W. (2019) Improving the experimental teaching of plant biology and improving student participation. Journal of Educational Theory, (22), 77-78.

He, S., \& Abasi, A. (2012) Strengthening practical teaching of plant biology to cultivate applied innovative talents. Education reform and Innovation, (4), 134-135.

Jia, G. (2016). Reform and practice of experimental teaching of plant biology. Education and Teaching Forum, 1(2), 244-245.

Li, D., Ye, A., \& Zhang, J. (1998). Experimental teaching in classroom teaching of botany. Higher Agricultural Education, (1), 7 .

Li, J., Zhou, S., \& Zhou, L. (2015). Application of task-driven teaching method in biotechnology experimental course teaching. Science and Education Guide, (11z),100-101.

Li, Y. (1999). Exploring the application of teaching method in botany experimental teaching. Henan Science, (1), 224.

Liang, X., Li, L., \& Li, G. (2012). Exploration on experimental teaching reform of plant biology. Education reform and Innovation, (7), 48-50.

Liu, Y. (2010). Discussion and practice on teaching reform of plant biology. Reform and Opening up, (20), 131-132.

Lu, Z., \& Zhou, W. (2013). Innovative exploration and research on practical teaching of plant biology. Journal of Hengshui University, 2(1), 93-94.

Su, G., Zeng, J., \& Feng, H. (2016). Management and teaching practice of integrated experiments in plant biology. Journal of Anhui Agricultural Sciences, (28), 252-253. 
Tan, L. (2012). The exploration of improving the effectiveness of botany classroom teaching. Examination Week, (53), 164-165.

Teng, H. (2013). Practical teaching system reform of four-in-one plant biology. Journal of Yuncheng University, 31(2), 59-62.

Teng, L., Meng, Q., \& Lu, J. (2007). Research and practice on the construction of national Biological experimental teaching demonstration center. Chinese University Teaching, (7), 36-38.

Wang, G. (2009). Plant experimental teaching reform. Modern Agricultural Science and Technology, (19), 343-344.

Wang, J., Cao, H., \& Jiang, X. (2000). Discussion on teaching methods of botany in biology department of Normal University. Journal of Railway Teachers College, (2), 48.

Wang, X., Chen, Q., \& Shi, J. (2009). Exploration and reform of plant biology practice teaching. Journal of Anhui University of Science and Technology, 23(1), 74-76.

Wang, Z., Li, W., \& Zuo, H. (2009). Student-centered training of autonomous learning in open experiment. China Modern Educational Equipment, (15), 66.

Xiao, J., Hong, C., \& Shi, C. (2001). Improving the teaching quality of genetics experiment based on innovation. Higher Agricultural Education, (S1), 99.

Yang, Y., Tang, P., \& Chen, Y. (2018). Experimental teaching reform of plant biology in agricultural colleges and universities. Journal of Yunnan Agricultural University (Social Sciences), 12(1), 100-104.

Yi, L., Wang, P., \& Cheng, H. (2011). Genetic experimental teaching reform and innovative talent training. China Modern Educational Equipment, (3), 93.

Yi, X. (2013). On the innovative mechanism of plant biology practice teaching. Educational Reform and Innovation, (47), 35-36.

Yu, S., Li, J., \& Wang, J. (2010). Application of inquiry-based teaching in plant biology teaching. Education and Occupation, (12), 158-159.

Yuan, Y., Liu, N., \& Chen, C. (2020) Application of "Internet + Task-driven" in experimental teaching of plant biology. Education and Teaching Forum, (15), 391-392. https://doi.org/10.1386/ctl_00042_5

Zhang, G. (2015). Application of smart phone in undergraduate teaching practice of plant biology experiment. Higher Science Education, (4), 108-110.

Zhang, Y., Meng, L., Cheng, Y., Liu, Y., Yan, G., \& Jiang, D. (2016) Experimental teaching reform and practice of plant biology. Experimental Teaching, 2016(20), 132-134.

Zhou, L. (2000). Experimental teaching reform in colleges and universities. Journal of Huainan Institute of Technology (Social Science Edition), 3(2), 94-96.

Zhou, Y., Jin, C., \& Bai, J. (2019) Teaching reform of professional basic courses under application-oriented talent cultivation mode. Modern Agricultural Science and Technology, 2019(2), 229-230.

Zhu, L., Hao, S., \& Xu, C. (2015). A Preliminary study on the teaching reform of basic courses for business administration majors in Local Application-oriented universities: A case study of Anhui University of Science and Technology. Education and Teaching Forum, 2015(10), 103-104.

Zou, Z., Deng, R., \& Duan, X. (2014). Integration of classroom teaching and Network resources in plant biology course. College Biology Teaching research, 4(2), 29-31.

\section{Copyrights}

Copyright for this article is retained by the author(s), with first publication rights granted to the journal.

This is an open-access article distributed under the terms and conditions of the Creative Commons Attribution license which permits unrestricted use, distribution, and reproduction in any medium, provided the original work is properly cited. 